\title{
IMPACT IN THE AGRO-FOOD AND BIO-ECONOMY DOMAIN
}

UNO SVEDIN AND BETTINA HEIMANN

DOI: $10.22163 /$ fteval.2019.339

\section{ABSTRACT}

$\mathrm{T}$ he focus of this paper is to reflect on the issue of "impact" of $R g l$ in the agro-food and bio-economy domain (AF-BE) - fields that have a long tradition for such concerns. However, the relevant approaches have changed over time due e.g. to technical developments, globalization and related changes and preferences in society at large. Accordingly the respective features of impacts - and connected indicators to assess them - have to find new forms as well. These considerations are clearly seen in the implementation of the SDGs within the chosen domain. The resulting needs for R\&l policy and connected impacts in the AF-BE fields are discussed.

\section{INTRODUCTION}

The issue of "impact" in relation to national and EU-level research and innovation has been present for quite some time, but attention in policy circles has gradually increased year by year often targeting specified policy aims. It is a common procedure to assess investments in research - not least in fields of applied research which rely heavily on the innovation capacity with regard to new technologies. This, includes integrating technologies developed in other fields in an innovative way as well as structural innovations (e.g. institutional and organizational) - to increase efficiency and competitiveness in a given sector. These considerations have since long had an important role when formulating research policy at European and national levels in agro, food and bio-economic fields (also involving forestry and fisheries). This research and innovation domain is at the focus of this paper, both providing a brief outline of the tendencies within these realms, but also as a contribution to the more general debate about the use and role of such considerations in research and innovation policy, i.e. about "impact" at large.

\section{BACKGROUND}

After WW II - and onwards - promoting food production and securing availability were the overriding policy aims in Europe with a strong focus on:

a. the optimization of the production systems, based on crop production as well as animal production, including their relationship to varying conditions; This traditional field is characterized by pin pointedly identified research and innovation objects often related to optimization of various parts of a production systems, e.g. crop development,under certain soil conditions or new efficiencies related to animal production and connected animal health aspects. Not least quickly expanding micro biological and genetic methodological capacities have been strong drivers for innovation and associated impacts in these fields. Many of these types of results of research and innovation efforts have been brought into farm practice through specifically designed agricultural knowledge and innovation structures organized at national and regional levels. These tools and mechanisms are still valid, but in a modified way since the character of the challenges for the sector have expanded over the decades and thus targets have changed accordingly. New and partially different research and innovation backgrounds have come into the picture, and thus also partially new targets and methods have been needed such as those outlined below:

b. the maintenance of the resilience of these systems facing changing weather and climate conditions, water availability and pest infestations and diseases.

c. the consideration of the systemic inter sectoral connectivity of the agro-food and bio-economy fields, e.g. with energy, land use, food and health domains.

d. the relation between agricultural activities and their societal embedding, i.e. trade, socio-economic aspects, consumer behavior, urban-rural connections in planning etc.

There has been a growing interest in all these categories.

\section{GRAND CHALLENGES - EMERGING INTEREST ARENAS}

Due to the quickly expanding need to address "the grand challenges of our times" - a strong interest has grown to invest in research explorations of large webs of phenomena such as climate change (e.g. IPCC, 2018); tightening supplies of energy, water and food; public health and pandemics and herby widening their general understanding and injecting new and fresh perspectives into the sector related research. This has also become a very important part of the EU's research strategy during the last decade (not least after the Swedish EU presidency conference with the Lund declaration, 2009). One exemplification on how research in the traditional arena of food and agriculture is changing is demonstrated through its presence as a central part of the new bio-based economy concept and ongoing reflections about emerging possibilities of a circular economy. These arenas are examples of quickly expanding efforts in binding together all sorts of considerations about bio-based resources 
on land (including both agriculture and forestry) as well as of the aquatic environments. In the following some examples are indicated:

a. the new connections as e.g. the link between food and forestry domains are introducing food (and feed) possibilities from forestry products - or as new types of support functions to the food industry by increasing systemic recycling from one domain to another (Sandeep, 2018).

b. the innovations due to digitalization and various forms of computer guided "precision farming" and evolving artificial intelligence (Al) practices are providing an expanding set of new tools - but also new challenges

c. the above described considerations are also embedded in new challenges in regional development when re-connecting urban and rural relations in new forms (e.g. more urban oriented food production lines) (Svedin and Liljenstrom, 2018). As an overriding reflection about these and other new aspects with regard to this particular field of R\&l it could be said that the appropriate style and balance has to be discussed between on the one side finding more specific strict targeting in relation to pin pointed research and innovation objects - and on the other hand widening the exploration about the contexts, drivers and transformative features of broad sets of phenomena.

\section{DIFFERENT AIMS WITH REGARD TO "IMPACT IDENTIFICATION"}

The balance issue in a policy sense has implications for the considerations about how to handle quite diverse forms of ambitions and targets - also in terms of potential impacts.

\section{1. "IMPACT" IN TERMS OF PIN-POINTED EFFICIENCY DRIVEN RESEARCH TARGETS}

The more partially targeted aims of a technical nature have as research and innovation objectives a different character than many of the systemic oriented 'grand challenges' targeted ones. Concerning pin-pointed research efforts e.g. the technology readiness level (TRL) scale has been employed to provide a structure to the innovation efforts and processes in the EU framework program Horizon 2020 (European Commission, 2014). Concerning the AF-BE domain - where several players contribute to the introduction of an innovation - the scale helps to clarify their respective positions in the range from concept to adoption. This method could also help to define the competencies, funding mechanisms, drivers and deliverables related to each position on the TRL scale. Thereby it could be used to highlight cooperation opportunities between different types of actors and the management of those opportunities. Thus the TRL scale can help researchers to define the 'end-users' of their future research results and to clarify which type of partners they should collaborate with to achieve the highest and most relevant impact with their respective research in order to solve e.g. a particular technological bottleneck or develop an innovative procedure for increased efficiency. It could thus also be used as a means to illustrate more clearly to a variety of research funders what the particular contribution could be in terms of intended impacts.

\section{2 "IMPACT" IN TERMS OF EX-ANTE CONSIDERA- TIONS}

The broad systemic oriented objects of inquiry are different in terms of aims, institutional embedding, as well as the style of methods and approaches applied. Consequently, there is a strong need for further development of indicators of relevant impacts in all the traditional, but in particular also with regard to the more recently emerged and emerging cross linked phenomena since all these areas of concern have different criteria of success and failure. Target setting for impact is a constant process where obtained knowledge in the form of achieved results and development of new and emerging technologies from earlier development cycles are the basis for the next step of target setting and strategizing. Therefore the question of impact can be looked at either from an 'ex-ante' or 'ex-post' position. In the case of an ex-ante approach "impact" means "potential impact" and thus depends on what priorities will be taken, which strategies are set in motion and which decisions are made that will influence the development of a particular outlined research program (at different institutional levels:, subnational, national, European and global). Hence it will influence the opportunities of technological development in a certain field in various ways depending on design, operational approaches and context. It also might influence the management of future research institutions and the systemic effects framing entire sub-branches of a certain policy complex. Thus a research/ innovation proposal needs to consider what could be addressed immediately and what is less urgent, e.g. with reference to various measures to handle alternative. In the operational ex ante phase the selection of key research and innovation structures to investigate the prioritized issues are of strong importance. They will define what the chances are that a certain framing of a systemic challenge can deliver adequate answers in a solution oriented manner and at the right time. They will also influence what kind of measures and structures are needed to interact with stakeholders and how to disseminate possible outcomes (which activity potentially might need its own financing).

\subsection{EX-ANTE AND FORESIGHT EFFORTS}

In the last decades 'foresights' have become an important tool to scan and define the overarching issues and concerns that need to be addressed and can be used to create a common prioritizing. It is usually the research policy community together with research institutions and with other important actors and stakeholders - often industry but also civil society representations - that are part of the process. Within the broader agro food and bio-economy field for example a series of foresights have been conducted. Some have been driven by EU related bodies as the Standing Committee of Agricultural Research (SCAR) (e.g., the EU-SCAR $3^{\text {rd }}$ foresight report in 2011 and the $4^{\text {th }}$ in 2015 and the EU/ JRC Science and Policy reports (e.g. "Global Food Security 2030 - Assessing trends with a view to future EU policies", 2015) . At the global level studies conducted by UN related bodies could be exemplified (e.g. FAO, "The future of food and agriculture - Trends and challenges", 2017) and the OECD (e.g. "Alternative futures for Global Food and Agriculture", 2016). These types of bodies undertake regularly such scanning as do national bodies (e.g. UK Government Office for Science: "The Future of Food and Farming", 2011) (and the Irish research body Teagasc study from 2016: "Teagasc Technology Foresight 2035"). In all these studies the central aim is to define: 
- What are the core issues?

- What are the major drivers?

- Who are the key actors?

Foresights are used as an instrument to reflect on the most pressing challenges at the respective level of investigation and the type of impacts being of interest.

\subsection{EX-POST ISSUESWITH REGARDTO AGGREGATES}

In the case of an ex-post approach the point of departure is the assessment of a set of already created aggregates of research and innovation investments and institutionalizations that have been materialized within a certain past time frame, e.g. somewhat longer than the length of a "normal" research program at national and European level evaluating the various impacts on society achieved by the particular selected set of activities. It is important to note that it is not easy to identify immediately any profound impact within a short time frame after the formal end of the activities under scrutiny, in particular not any changes of a transformative kind that influence the ways things will be done differently or how structures deeply have been transformed. Therefore evaluation investigations have to be undertaken in a sequence of steps (e.g. after 3-5-10 years) that map and put in perspective what have been the outcomes and why or why not the initial aims were achieved. Strong reflection capacities are required and structures have to be available to make such reflections. Causality flows for research investments have to be investigated, i.e. comparing the reasoning at the input side why certain impacts at that time were expected (given the organizational and financial set up) with the outcome much later. This should also explore something about the societal dynamics, i.e. through which efforts aiming for some transformational steps later emerged as manifested changes (including non intentional ones). Numerous evaluation and assessment reports of research programs at national as well as European level (e.g. H2020 Interim Evaluation, 2018) are based on such ex-post approaches. However they are often conducted as mid- and end-term evaluations and therefore do not catch the longer-term impacts - neither those intended nor the undesired ones - thus being beyond the immediate research results (including processes and management). One example for a systematic approach to map impact against investment (financial as well as intellectual) at a longer term is the "asirpa" approach developed by INRA to assess the institution's research efforts against socio-economic impact gained (M. Matt et al., 2017).

\section{THE IMPLEMENTATION OF THE SDGs - IMPACTS WITHIN A GLOBAL CONTEXT}

Since the UN adopted the global Sustainable Development Goals (SDGs) for the period until 2030 and beyond up to 2050, these have become a core concept of European and national funding strategies within a global context. Science, technology and research within the field of the bio-economy and the agro, food, aqua, and forest sector(s) are key means to the overall implementation of the SDGs and thus provide ways to reach these goals. One particularity of the sector under discussion in our context is that it both provides challenges to some of the SDGs, but also at the same time is vital to the possibility to reach many of these other goals. As the SDGs are interlinked in many ways and are operating at different levels, their implementation calls for scientific and technological solutions that match such considerations. There are and will be a multitude of actors with different interests, perceptions and backgrounds involved in the process - also at different levels (IIASA, 2018). A systems approach to sustainable agriculture needs to be further developed in the service of finding overarching solutions in the SDG context. It should take into account the diversity of interactions among humans and the environment, so much at the needed core of the considerations for the future of the agricultural sector. Such reasoning is reflected e.g. in a paper by Patrick Caron et al. (2018) looking at food systems to ensure sustainable development since they link climate, agriculture and food.

The challenge how to measure impact in such a broader frame has to be given much and extended attention. A first step is to find relevant impact indicators for the different levels. But the reflection has to go beyond the multi layered analysis since complex systems are dynamic and technological developments and their societal framings - depending on context - might temporally have to be strongly in tune with the dynamic requests of the solutions, as e.g. the climate challenges so clearly demonstrate. Follow-up questions are

- How to adapt - and even construct - relevant indicators when new practices are starting to be established and new knowledge is emerging?

- How to ensure that policies focusing on global priorities such as the SDGs do consider that these needed actions may have unintended or unexpected consequences in an array of other sectors than those connected with agriculture?

\section{CONCLUDING REMARKS}

Thus systems considerations have to be kept in mind as well as the various effects on regional/local realities in a globalized world; also the multiple functions of and impacts from agriculture with regard to socioeconomic and ecological resilience need to be highlighted. Research and innovation strategies have to take all these aspects into account. Thus there is a need for a much broader array of disciplines and transdisciplinary efforts to be engaged. In addition new types of project partners are called for in service of new research approaches. In this context a few principal questions need to be addressed:

- How to integrate an increased reflexivity capacity into the overall research system?

- How to mobilize a sufficiently broad set of relevant actors?

- How to understand the different roles of actors?

- How could we create relevant frameworks of exploration of these issues and provide mechanisms for societal experimentation?

At the same time also strategic funding has to reflect these needs. Policies have to be designed and implemented that permit the mobilization of the necessary innovative capacities. Also there is a need to enhance reflective processes around these systemic concerns in the research community at large. This also implies finding new platforms to address the design aspects of relevant assessment processes. With the formulation of the grand challenges at European level and the adoption of the 2030 UN Agenda for Sustainable Development at global level the systemic and nexus based policy targets have become more widely - but not totally - accepted, as has the understanding that research approaches and programs have to reflect these concerns. However, traditional research areas are still of continued importance, although new methodologies and approaches need to be developed also for their purposes. 
The necessary indicators to measure transformational progress are still underdeveloped and need much more methodological thought, practice development and new institutional innovations and strategic support.

\section{ACKNOWLEDGEMENT}

The two authors would like to recognize the strong influence and the discussions and policy formations by the European NGO EURAGRI (www.euragri.aau.dk). During the years of EURAGRI activities (especially during the last 10 years) considerable contributions around themes as those covered in this article have been voiced in annual conferences, supportive workshops, and through informal networking. We are deeply indebted to all our colleagues, because without their contributions and skills our understanding would have been much more limited. This involves also the contacts over years with central decision makers at many levels who have contributed understanding of the policy world and shown how the handling of important issues for our common future needs the combination of knowledge production and societal decision making with strong focus on the challenges involved. However, the responsibility for the present paper lies entirely with the two authors.

\section{REFERENCES}

Bergeret, P.; Svedin, U. and Valescini, E. (ed.) (2018). Bio-economy challenges and implementation - the European research organisations' perspective. Éditions Quæ, Paris.

Caron, P. et al. (2018). Food systems for sustainable development: proposals for a profound four-part transformation. Agronomy for Sustainable Development 38: 41 https://doi.org/10.1007/s13593-018-0519-1

European Commission (2018). Horizon 2020 Interim Evaluation - Maximizing the Impact of EU Research and Innovation, https://ec.europa.eu/ research/evaluations/index.cfm?pg=h2020evaluation

European Commission (2014). Horizon 2020 - work program 2014-2015 General Annexes https://ec.europa.eu/research/participants/data/ref/ h2020/wp/2014_2015/annexes/h2020-wp1415-annex-g-trl_en.pdf

European Commission, Standing Committee on Agricultural Research (SCAR) (2015). The 4th SCAR Foresight Exercise (FEG4) (expert report), "Sustainable Agriculture, Forestry and Fisheries in the Bioeconomy - A Challenge for Europe", http://ec.europa.eu/research/scar/pdf/ feg4-draft-15_may_2015.pdf

European Commission, Standing Committee on Agricultural Research (SCAR) (2011). The 3rd SCAR Foresight Exercise (FEG3) (expert report), "Sustainable food consumption and production in in a resource constrained world", https://ec.europa.eu/research/scar/pdf/scar_3rdforesight_2011.pdf

FAO (2017). The future of food and agriculture - Trends and challenges, http://www.fao.org/global-perspectives-studies/resources/detail/ en/c/458158/
Huyghe, C.; Bergeret, P. and Svedin, U. (ed.) (2016). Diffusion and transfer of knowledge. Éditions Quæ, Paris.

IIASA (2018). TWI2050 Report: Transformations to achieve the Sustainable Development Goals, http://www.iiasa.ac.at/web/home/research/ twi/Report2018.html

IPCC (2018). Global Warming of 1.5 OC, Special report, IPCC, 2018.

JRC Science and Policy reports (2015). Global Food Security 2030 Assessing trends with a view to future EU policies, https://ec.europa.eu/ jrc/en/publication/eur-scientific-and-technical-research-reports/globalfood-security-2030-assessing-trends-view-guiding-future-eu-policies

Matt, M.; Gaunand, A.; Joly, P.-B. and Colinet L. (2017). Opening the black box of impact - Ideal-type impact pathways in a public agricultural research organization. Research Policy, 46(1), 207-218. D0I: 10.1016/j. respol.2016.09.016.

OECD Publishing (2016). Alternative Futures for Global Food and Agriculture. https://read.oecd-library.org/agriculture-and-food/alternativefutures-for-global-food-and-agriculture_9789264247826-en\#page1

Sandeep, S. (2018). Production of microbial protein from brown seaweed and spruce wood and its use as a novel feed ingredient in aquaculture. : NMBU 2018 (ISBN 978-82-575-1518-8).

Svedin, U. and Liljenström, H. (2018). A Multilevel Approach to Urban Regional Agglomerations: A Swedish Case of Transition Paths toward a "Fossil-Free Society" by 2050 in: Urban Agglomeration Mustafa Ergen, Intech0pen, DOI: 10.5772/intechopen.73104.

https://www.intechopen.com/books/urban-agglomeration/a-multilevelapproach-to-urban-regional-agglomerations-a-swedish-case-of-transition-paths-toward-a-f

Swedish EU Presidency Lund Declaration (2009). https://era.gv.at/ object/document/130

Teagasc (2016). Teagasc Technology Foresight 2035, https://www. teagasc.ie/media/website/publications/2016/Teagasc-Technology-Foresight-Report-2035.pdf

UK Government Office for Science (2011). The Future of Food and Farming, Final report, London, https://www.gov.uk/government/publications/future-of-food-and-farming 


\section{AUTHORS}

\section{UNO SVEDIN}

Stockholm Resilience Centre, Stockholm University

Kräftriket 2B, SE-10691 Stockholm, Sweden

EURAGRI, Aalborg University

Fredrik Bayers Vej 7H, 9220 Aalborg Øst

E: uno.svedin@gmail.com

\section{BETTINA HEIMANN}

Department of Chemistry and Bioscience, Aalborg University

Fredrik Bayers Vej 7H, 9220 Aalborg Øst, Denmark

E: bhe@bio.aau.dk

EURAGRI, Aalborg University

Fredrik Bayers Vej 7H, 9220 Aalborg Øst

Keywords: Impact of R\&I - Agro-food sector - bio-economy - Circular economy - Grand challenges - Ex ante and ex post assessments - EU policy - Sustainable Development Goals
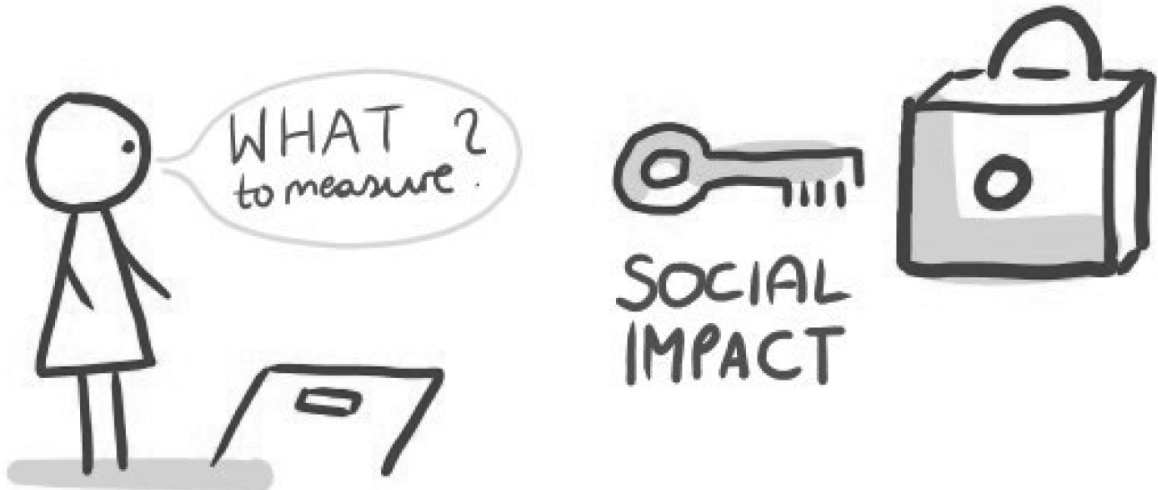